\title{
Sparse coding representation of emotional brain states in $\mathrm{fMRI}$ data
}

\author{
Amir Madany Mamlouk ${ }^{1,2^{*}}$, Silke Anders $^{3}$ \\ From Nineteenth Annual Computational Neuroscience Meeting: CNS*2010 \\ San Antonio, TX, USA. 24-30 July 2010
}

Modern computer systems can deal with tremendous amounts of information, and these systems are becoming more and more complex. Still, there is no machine that develops emotions when processing complex stimuli. In this respect, processing in the human brain seems to differ from processing in machines not so much in the amount of data dealt with, but especially in terms of the global integration of parallel (local) processes as a whole [1].

FMRI (functional magnetic resonance imaging) is a method that gets us "behind the scenes" even if participants perform complex tasks. As "complex" refers to tasks that cannot described by activity in a single locus, multivariate techniques are the first choice on the way to break the code underlying these responses. Standard factor analysis is used to determine, in which of the brain regions activity is correlated (PCA) or which voxels are showing statistical independent activity (ICA) $[2,3]$. But on the way to understand such patterns, we are especially interested in the intrinsic organization of these correlated or statistical dependent modules. In this context, the use of Sparse Coding (SC) is twofold: We could try to find class-separating feature vectors that are sparse but still discriminative for the given classes [4]. But just the same, we can learn a set of base functions - alternatively to PCs and ICs - that resembles the task-specific patterns by a linear combination with as few as possible non-zero coefficients [5].

We analyzed an fMRI study to examine the brain responses to emotional conditions (anger, fear, surprise, joy, and sadness) and focused on the impact of sparse coding to the pattern characterization task.

We show how the structure of global brain activity and how the complexity of sparse patterns is changing during different emotional states and that different affective

* Correspondence: madany@inb.uni-luebeck.de

${ }^{1}$ Institute for Neuro- and Bioinformatics, University of Lübeck, Germany states of the system can be well discriminated using SC. Finally, we will address the question of how many voxels are needed to discriminate these emotional states.

\section{Author details}

'Institute for Neuro- and Bioinformatics, University of Lübeck, Germany.

${ }^{2}$ Graduate School for Computing in Medicine and Life Sciences, University of Lübeck, Germany. ${ }^{3}$ Department of Neurology and Neuroimage Nord, University of Lübeck, Germany.

Published: 20 July 2010

\section{References}

1. Tononi G: An information integration theory of consciousness. BMC Neuroscience 2004, 5:42.

2. Zhong $Y$, Wang $H$, Lu G, Zhang $Z$, Jiao $Q$, Liu $Y$ : Detecting functional connectivity in fMRI using PCA and regression analysis. Brain Topogr 2009, 22(2):134-144.

3. Calhoun VD, Liu J, Adali T: A review of group ICA for FMRI data and ICA for joint inference of imaging, genetic, and ERP data. Neuroimage 2009 45(1 Suppl):S163-S172.

4. Yamashita O, Sato M, Yoshioka T, Tong F, Kamitani Y: Sparse estimation automatically selects voxels relevant for the decoding of fMRI activity patterns. Neurolmage 2008, 42:1414-1429.

5. Labusch K, Barth E, Martinetz T: Sparse Coding Neural Gas: Learning of Overcomplete Data Representations. Neurocomputing 2009, 72(79):1547-1555.

doi:10.1186/1471-2202-11-S1-P85

Cite this article as: Mamlouk and Anders: Sparse coding representation of emotional brain states in fMRI data. BMC Neuroscience 2010 11(Suppl 1):P85.

Submit your next manuscript to BioMed Central and take full advantage of:

- Convenient online submission

- Thorough peer review

- No space constraints or color figure charges

- Immediate publication on acceptance

- Inclusion in PubMed, CAS, Scopus and Google Scholar

- Research which is freely available for redistribution 